\title{
Assessment of geometry in 2D immune systems using high accuracy laser-based bioprinting techniques (Conference Presentation) (Withdrawal Notice)
}

Sara Lauzurica, Andrés Márquez, Carlos Molpeceres, Laura Notario, Miguel Gómez-Fontela, et al.

Sara Lauzurica, Andrés Márquez, Carlos Molpeceres, Laura Notario, Miguel Gómez-Fontela, Pilar Lauzurica, "Assessment of geometry in 2D immune systems using high accuracy laser-based bioprinting techniques (Conference Presentation) (Withdrawal Notice)," Proc. SPIE 10062, Optical Interactions with Tissue and Cells XXVIII, 100620Q (25 January 2018); doi: $10.1117 / 12.2253622$

SPIE. Event: SPIE BiOS, 2017, San Francisco, California, United States 


\section{Assessment of geometry in 2D immune systems using high accuracy laser-based bioprinting techniques (conference presentation) (withdrawal notice)}

Sara Lauzurica, Andrés Márquez, and Carlos Molpeceres

Universidad Politécnica de Madrid (Spain)

Laura Notario, Miguel Gómez-Fontela, and Pilar Lauzurica

Centro Nacional de Micrbiologia, Instituto de Salud Carlos III (Spain)

Universidad Politécnica de Madrid (Spain)

Proc. SPIE 10062, 100620Q (2017)

Online Publication Date: 19 April 2017

Withdrawn from Publication: 25 January 2018

Conference Date: 30 January-31 January 2017

Conference Location: San Francisco, California, United States

Conference Title: Optical Interactions with Tissue and Cells XXVIII

Conference Chairs: E. Duco Jansen, Hope T. Beier

Publisher's Note: This conference presentation, originally published on 19 April 2017, was withdrawn per author request. 